\title{
Microstructure Modification of Powder Compact of Al-Zn-Mg Nanostructured Alloy by a Semisolid Thermomechanical Processing
}

\author{
Mohsen Hajizamani $^{1} \cdot$ Mostafa Alizadeh $^{1} \cdot$ Seyed Ahmad Jenabali-Jahromi $^{2}$
}

Received: 12 August 2015/Revised: 25 October 2015/Published online: 4 January 2016

(C) The Chinese Society for Metals and Springer-Verlag Berlin Heidelberg 2015

\begin{abstract}
A thermomechanical process (TMP) consisting of three cycles of cold pressing at $154 \mathrm{MPa}$ and liquid-phase sintering at $600{ }^{\circ} \mathrm{C}$ for $30 \mathrm{~min}$ in each cycle was applied to modify the microstructure of nanostructured $\mathrm{Al}-\mathrm{Zn}-\mathrm{Mg}$ alloy. The alloy powders were produced by mechanical alloying. Also, solid-state sintering at $550{ }^{\circ} \mathrm{C}$ for 90 min was done to compare the results with those obtained from the TMP. The powders and the thermomechanically (TM) processed samples were analyzed by XRD to reveal the present phases in addition to calculating the crystallite size changes by the Williamson-Hall method. Moreover, scanning electron microscope was employed to observe the morphology of the powder and the microstructures of the sintered and the TM processed samples. The results revealed that the TMP affected the microstructure noticeably as well as the microhardness by removing the continuous grain boundary porosities and uniform distribution of the intermetallic phase particles as well as obtaining a near globular microstructure after the second cycle. Also, the average grain sizes in the first and the second cycles of the TMP were lower than those of the sintered sample. Furthermore, nanocrystalline grains were stable up to the second cycle of the TMP.
\end{abstract}

KEY WORDS: Thermomechanical processing; Al-Zn-Mg alloy; Intermetallics; Sintering; Grain growth

\section{Introduction}

Semisolid forming (SSF) has become one of the most accepted metal processing methods because of major advantages, such as nondendritic microstructure, the

Available online at http://link.springer.com/journal/40195

Mohsen Hajizamani

mohsen.hajizamani@gmail.com

$\triangle$ Mostafa Alizadeh

alizadeh@icst.ac.ir

1 Department of Metals, Institute of Science and High Technology and Environmental Sciences, Graduate

University of Advanced Technology, PO BOX 76315-115,

Kerman, Iran

2 Department of Materials Science and Engineering, School of Engineering, Shiraz University, PO BOX 71348-51154, Shiraz, Iran reduction in macrosegregation, porosity and low forming efforts $[1,2]$. Different kinds of SSF techniques have been used by researchers [3-9]. For example, Tzimas et al. [3] attempted to carry out semisolid forming of various kinds such as spray casting, magnetohydrodynamic (MHD) casting and strain-induced melt activation (SIMA) process on different $\mathrm{Al}$ alloys and concluded that alloys with lower ductility required warm working instead of cold working in the SIMA process. Haghayeghi et al. [4] modified the microstructure obtained by ordinary casting through mechanical stirring in A356.1 alloy and optimized the time and temperature of the process. Satyanarayana et al. [5] studied spray casting of LM25 and 6061 alloys and showed that fine equiaxed grains in the alloys and their composites can be obtained. Wang et al. [6] investigated the effects of semisolid isothermal holding heat treatment on 7075 alloy and found the influence of time and temperature of isothermal holding in the semisolid state. Wang et al. [7] employed partial remelting for AZ61 magnesium alloy and 
improved the microstructure effectively by cyclic extrusion in addition to partial remelting. Semisolid forming of SIMA type is more popular among researchers since this method has commercial advantages of simplicity and low equipment costs. Hassas-Irani et al. [8] studied the effect of SIMA process on A356 alloy and modified the microstructure. Jufu et al. [9] performed SIMA process on AM60 magnesium alloy to change the dendritic microstructure to the equiaxed one. Also, they found the optimum holding time in the semisolid state. Chen et al. [10] carried out SIMA process on AZ61 magnesium alloy to determine the effect of predeformation on the semisolid structure. They found out that nondendritic structure can be obtained by both cold and hot predeformation.

In general, these methods aim at changing the microstructure from dendritic to globular [11, 12]. However, the SIMA process consists of some stages, the first of which is casting in order to obtain dendritic structures [11]. Therefore, such a process cannot be performed on the powder compacts because basically no dendrites exist in the powder state.

To manufacture bulk samples, tools and workpieces from powders, it is necessary to perform sintering. Basically, sintering processes can be divided into two types: solid-state sintering and liquid-phase sintering. Solid-state sintering occurs when the powder compact is densified wholly in a solid state at the sintering temperature, while liquid-phase sintering occurs when a liquid phase is present in the powder compact during sintering [13], i.e., it occurs in the mushy zone. Compared with solid-state sintering, liquid-phase sintering (LPS) allows easy control of microstructure and reduction in processing cost [13]. However, it may degrade some important properties such as mechanical properties since the presence of the liquid phase may cause grain coarsening and nonuniform distribution of the intermetallic phases. Hence, it seems that applying a thermomechanical process (TMP) including more than a single cycle, which means combination of a mechanical working along with a heat treatment cycle, can overcome the problems of using only LPS process. Achievement in controlling the microstructure arisen from the powder means enhancing and commercializing the applications of powder metallurgy in different industries. On the other hand, most of the studies about the LPS in the literature focused on the ceramics and refractory materials $[14,15]$ using an additive to form the melt which causes densification [16]. Therefore, to the best of the authors' knowledge, using a process involving LPS on $\mathrm{Al}$ alloys can be a novel work in the field of P/M science and technology.

This research is aimed at developing a thermomechanical process involving alternate cold pressing and liquidphase sintering for powder compacts which is easy to use and cost-effective due to using simple equipment. Al-Zn$\mathrm{Mg}$ alloys have been broadly studied, and as mentioned by
Jiang et al. [17], Sharma et al. [18] and Flores-Campos et al. [19] in the literatures, they are used in the structural applications such as aerospace and automotive fields due to their high-strength-to-weight ratio, excellent mechanical properties and good wear and creep resistance. Also, there is almost no report about application of semisolid techniques to modify $\mathrm{Al}-\mathrm{Zn}-\mathrm{Mg}$ alloys in the literature. In addition, compared with the conventional solid-state sintering, this new TMP process led to a modified microstructure with nanocrystalline near globular grains and the least amount of isolated porosities as well as uniform distribution of intermetallic phase particles.

\section{Experimental}

Mechanical alloying of the elemental powders including $5.7 \mathrm{wt} \% \mathrm{Zn}, 2.7 \mathrm{wt} \% \mathrm{Mg}$ and $2.3 \mathrm{wt} \%$ other elements (including $\mathrm{Cu}, \mathrm{Mn}, \mathrm{Fe}, \mathrm{Si}$, Ti and $\mathrm{Ni}$ ) in addition to $\mathrm{Al}$ to synthetize the alloy powder for $40 \mathrm{~h}$ was carried out in a laboratory ball mill (Fritsch GmbH, model 'Pulverisette6') in a hardened chromium steel vial under argon atmosphere with the ball-topowder ratio of 20:1 and the rotational speed of $400 \mathrm{r} / \mathrm{min}$. Stearic acid ( $2 \mathrm{wt} \%)$ as the process control agent (PCA) was added to inhibit inappropriate cold welding. Then, the mechanically alloyed powders were compacted by cold uniaxial pressing in a cylindrical steel rigid die with graphite as a die lubricant. The solid-state sintering was carried out at $550{ }^{\circ} \mathrm{C}$ for $90 \mathrm{~min}$ for the powder compacts consolidated at $308 \mathrm{MPa}$ with the dimensions of $18 \mathrm{~mm}$ diameter and $5 \mathrm{~mm}$ height. The TMP was executed for three cycles. Each cycle consisted of cold pressing at $154 \mathrm{MPa}$ and liquid-phase sintering. The temperature chosen for the liquid-phase sintering was kept constant at $600{ }^{\circ} \mathrm{C}$, and the time for the LPS in each cycle was $30 \mathrm{~min}$. Both the solid-state sintering and the liquid-phase sintering were performed under argon atmosphere to avoid oxidation of the samples, and the heating rate for both cases was $3{ }^{\circ} \mathrm{C} / \mathrm{min}$. The thermomechanically processed samples were cooled slowly in the furnace. The temperature for the liquidphase sintering was determined by differential scanning calorimetry (DSC, NETZSCH STANETZSCH STA 409 PC/ PG) analysis under argon atmosphere with the heating rate of $5{ }^{\circ} \mathrm{C} / \mathrm{min}$ in the range of $585-645^{\circ} \mathrm{C}$. Figure 1 presents the DSC result of the alloy powders. For simplicity, nomenclatures were chosen for the sintered and the thermomechanically processed samples which are presented in Table 1.

Morphology of the mechanically alloyed powder sample and microstructures of the solid-state sintered and the thermomechanically processed samples were observed by a scanning electron microscope (SEM, Vega//Tescan). The SEM was equipped with Energy Dispersive Spectroscopy (EDS) to detemine the atomic percentage of the main elements. 


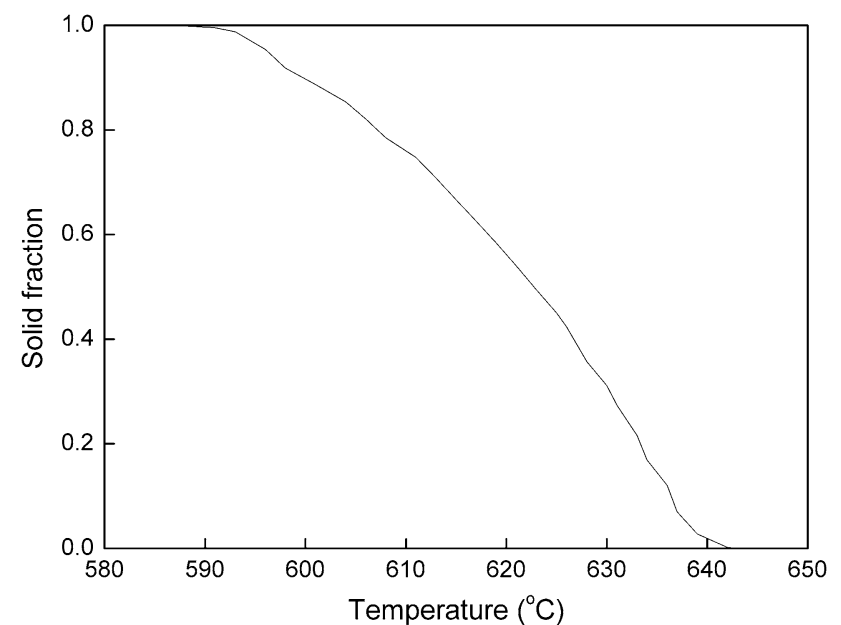

Fig. 1 Solid fraction versus temperature for the synthetized alloy from DSC analysis

Identification of the formed phases in the processed samples was done using a Bruker D8 advance diffractometer (XRD, $40 \mathrm{kV}$ and $40 \mathrm{~mA}$ ) and $\mathrm{Cu} K_{\alpha}$ radiation $(\lambda=0.154 \mathrm{~nm})$. The XRD patterns were recorded in the $2 \theta$ range of $20^{\circ}-90^{\circ}$ with the step size of $0.05^{\circ}$.

To investigate the stability of the nanostructured processed powder, the crystallite sizes of the powder and the bulk samples were calculated by the Williamson-Hall (WH) method for at least three peaks by

$\beta_{\mathrm{s}} \cos \theta=\frac{0.9 \lambda}{d}+2 \varepsilon \sin \theta$.

where $\beta_{\mathrm{s}}$ is the full width at half maximum of the diffraction peak, $\theta$ is the diffraction angle, $\lambda$ is the X-ray wavelength, $d$ is the crystallite size and $\varepsilon$ is the lattice strain. $\beta_{\mathrm{s}}$ can be calculated as:

$\beta_{\mathrm{s}}^{2}=\beta_{\mathrm{e}}^{2}-\beta_{i}^{2}$.

where $\beta_{i}$ is the width at half maximum of the Si powder peaks used for calibration and $\beta_{\mathrm{e}}$ is the evaluated width. Thus, a straight line with intercept $0.9 \lambda d$ and slope $\varepsilon$ is given by plotting $\beta_{\mathrm{s}} \cos \theta$ versus $\sin \theta$.

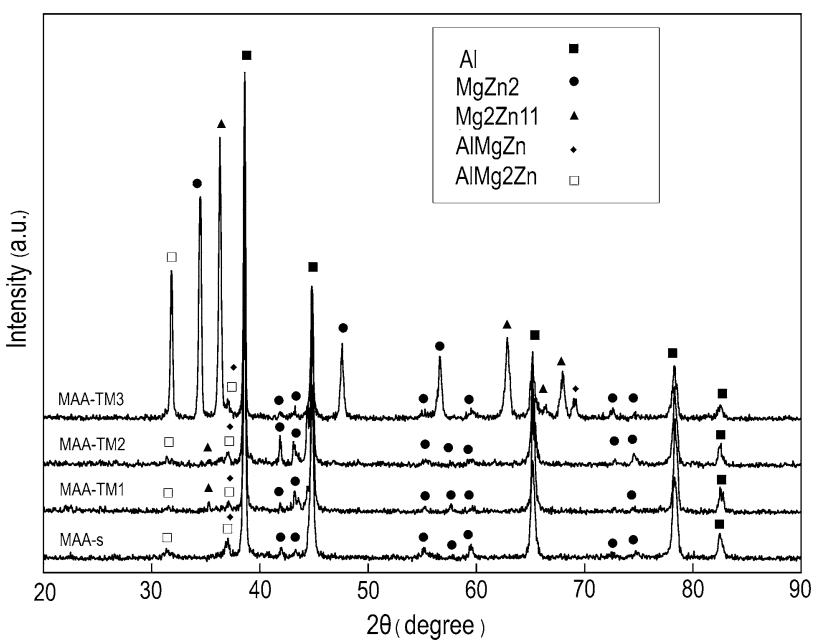

Fig. 2 XRD patterns of the solid-state sintered and the thermomechanically processed samples

The microhardness values of the samples were measured by a Vickers indenter at a load of $245 \mathrm{mN}$ and dwell time of $5 \mathrm{~s}$. At least six indentations on the samples were done to obtain the data of microhardness.

\section{Results and Discussion}

\subsection{XRD Results}

The XRD patterns of the samples presented in Fig. 2 show that the formed phases in all the samples were similar and only the amount of these phases may be different. This can be measured by calculating the area under the peaks of each phase. This area is dependent on the peak numbers and peak intensities. In MAA-s, the peaks of AlMgZn, $\mathrm{AlMg}_{2} \mathrm{Zn}$ and $\mathrm{MgZn}_{2}$ in addition to that of $\mathrm{Al}$ were detected. However, in the thermomechanically processed samples, $\mathrm{Mg}_{2} \mathrm{Zn}_{11}$ was also detected in addition to the mentioned phases. However, the equivalent peaks of this phase did not have the same intensity and location. In MAA-TM1 and MAA-TM2, the low-intensity peaks of

Table 1 Nomenclatures used for the samples in this research

\begin{tabular}{ll}
\hline Nomenclature & Process \\
\hline MAA-40 & $\mathrm{Al}-\mathrm{Zn}-\mathrm{Mg}$ powder mechanically alloyed for $40 \mathrm{~h}$ \\
MAA-s & $\mathrm{Al}-\mathrm{Zn}-\mathrm{Mg}$ powder cold-pressed under $308 \mathrm{MPa}+$ solid-state sintering at $550{ }^{\circ} \mathrm{C}$ for 90 min \\
MAA-TM1 & $\mathrm{Al}-\mathrm{Zn}-\mathrm{Mg}$ powder cold-pressed under $154 \mathrm{MPa}+$ modification process by LPS at $600{ }^{\circ} \mathrm{C}$ for 30 min \\
MAA-TM2 & $\mathrm{Al}-\mathrm{Zn}-\mathrm{Mg}$ powder cold-pressed under $154 \mathrm{MPa}+$ modification process by LPS at $600{ }^{\circ} \mathrm{C}$ for 30 min + cold-pressed under \\
& $154 \mathrm{MPa}+$ LPS at $600{ }^{\circ} \mathrm{C}$ for $30 \mathrm{~min}$ \\
MAA-TM3 & $\mathrm{Al}-\mathrm{Zn}-\mathrm{Mg}$ powder cold-pressed under $154 \mathrm{MPa}+$ modification process by LPS at $600{ }^{\circ} \mathrm{C}$ for 30 min + cold-pressed under \\
& $154 \mathrm{MPa}+\mathrm{LPS}$ at $600{ }^{\circ} \mathrm{C}$ for $30 \mathrm{~min}+$ cold-pressed under $154 \mathrm{MPa}+\mathrm{LPS}$ at $600{ }^{\circ} \mathrm{C}$ for 30 min \\
\hline
\end{tabular}


$\mathrm{Mg}_{2} \mathrm{Zn}_{11}$ were detected around $35^{\circ}$ and $36^{\circ}$, but in MAATM3 in addition to high-intensity peak around $36^{\circ}$, another peak around $63^{\circ}$ was observed. In other words, the TMP changed intensities of the formed phases and caused formation of a new phase. This can be related to the higher temperature of the TMP and the presence of the liquid phase, which resulted in longer diffusion distances and faster diffusion. However, in MAA-TM3, intensities of the observed peaks were completely different although similar phases existed. The most important change in this pattern was the decreased intensity of the main $\mathrm{Al}$ peak at about $38.5^{\circ}$. At the same time, the peak intensity of the Al-containing compound, i.e., $\operatorname{AlMg}_{2} \mathrm{Zn}$, increased. It can be stated that in the third cycle of TMP, more $\mathrm{Al}$ reacts with the other elements because the presence time of the liquid phase in MAA-TM3 was the maximum, i.e., $90 \mathrm{~min}$. The reduced intensity of the main $\mathrm{Al}$ peak can be observed in Fig. 3. In general, it can be concluded that as the presence time of the liquid phase increased more compounds containing $\mathrm{Al}, \mathrm{Mg}$ and $\mathrm{Zn}$ formed. Also, it can be seen in Fig. 3 that the main Al peaks for the thermomechanically processed samples have been shifted toward the lower angles. This demonstrated that the TMP caused residual stress in the samples due to solidification.

Another important result is about stability of the nanocrystallites during the solid-state sintering and the TMP. Figure 4 displays the crystallite size changes from the powder state to the third cycle of the TMP. As expected, the crystallite growth occurred by performing the solid-state sintering and the TMP. In the powder state, the crystallite size was $21 \mathrm{~nm}$. This size became $29 \mathrm{~nm}$ after the solid-state sintering. By performing the first cycle of the TMP, only $4 \mathrm{~nm}$ was the growth amount and crystallite size became $25 \mathrm{~nm}$. This may prove effectiveness of the liquid-phase presence in controlling the nanocrystalline structure. The crystallite sizes after the second and the third cycles of the

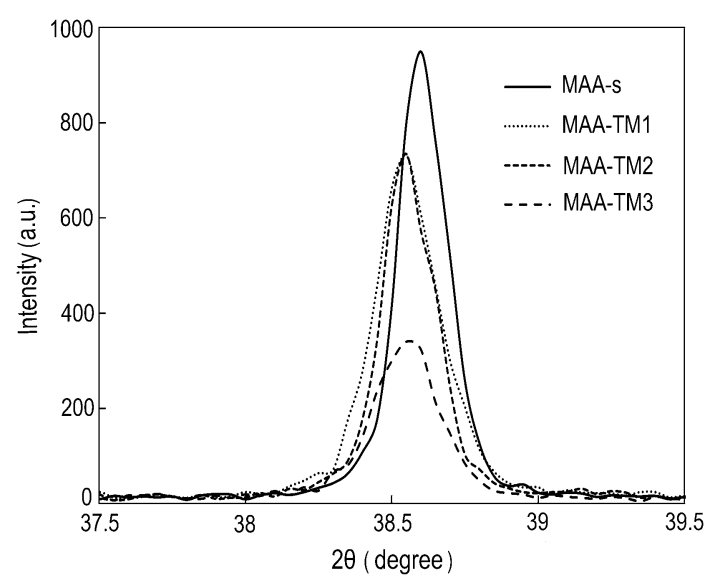

Fig. 3 Changes in the $\mathrm{Al}$ main peak from the solid-state sintering to the third cycle of the TMP

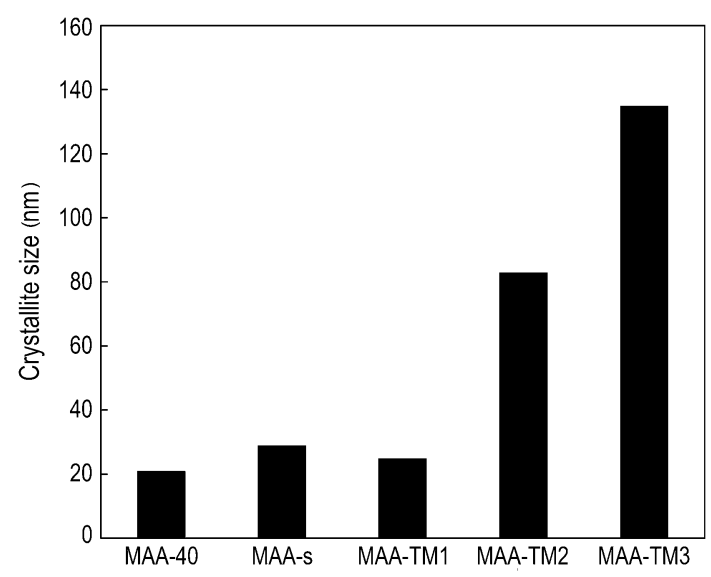

Fig. 4 Crystallite sizes of the solid-state sintered and the thermomechanically processed samples calculated by the $\mathrm{W}-\mathrm{H}$ method

TMP were 63 and $135 \mathrm{~nm}$, respectively. It shows that crystallite growth continued and finally in the third cycle the crystallites exit the nanocrystalline range (which is below $100 \mathrm{~nm}$ ). Nonetheless, the microstructure consisted of nanocrystalline grains up to the second cycle. This means that even with the presence of $10 \%$ of the liquid phase in the microstructure for $60 \mathrm{~min}$, nanocrystallites were stable. One of the main explanations for stability of nanocrystallites was the presence of porosities [20]. As will be discussed later, the amount of porosity decreased in the thermomechanically processed samples and this was the reason for crystallite growth in these samples and finally exiting the nanometric range in the third cycle.

\subsection{Microstructures}

Figure 5 exhibits the BSE images of the solid-state sintered and the thermomechanically processed samples. The leftsided images are from the surface perpendicular to the direction of pressure application and the right-sided ones are from the surface parallel with the direction of pressure application, i.e., the thickness of the samples. First, the leftsided images show the effects of sintering on the microstructures. In MAA-s, coarse grains with a noticeable amount of porosities in the grain boundaries can be observed. The connection between the grains was degraded by these porosities in some regions. In fact, these porosities appeared due to large pores between the agglomerated particles with small curvature and long diffusion distances which resist densification and slow down the sintering process [21]. The agglomerated particles can be seen in the morphology of the mechanically alloyed powder in Fig. 6. However, by performing the TMP, in MAA-TM1, the amount of porosities severely decreased. In the presence of the liquid phase, the diffusion rate increased, leading to a faster densification rate, grain growth and grain reshaping. 

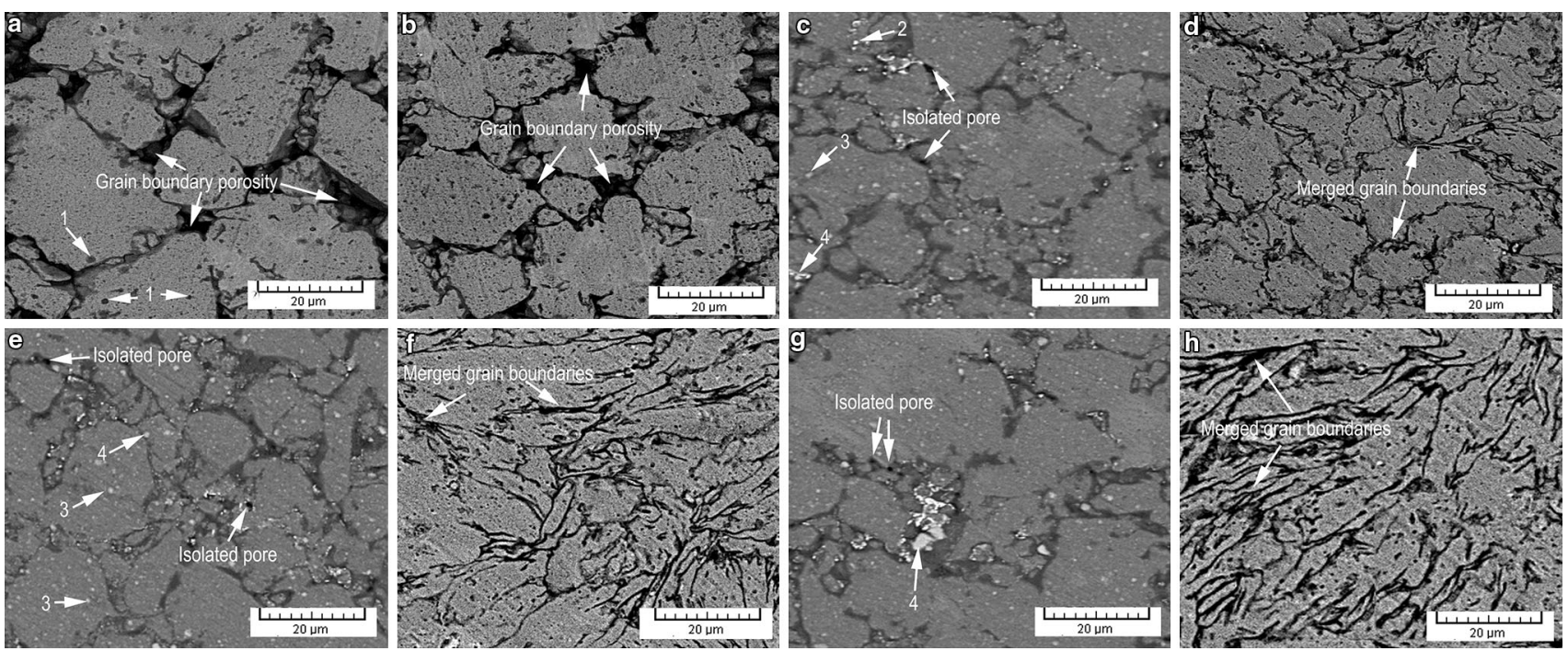

Fig. 5 The SEM images of the samples perpendicular and parallel to the pressure direction: a MAA-s, perpendicular; b MAA-s, parallel; c MAA-TM1, perpendicular; d MAA-TM1, parallel; e MAA-TM2, perpendicular; f MAA-TM2, parallel; g MAA-TM3, perpendicular; h MAATM3, parallel

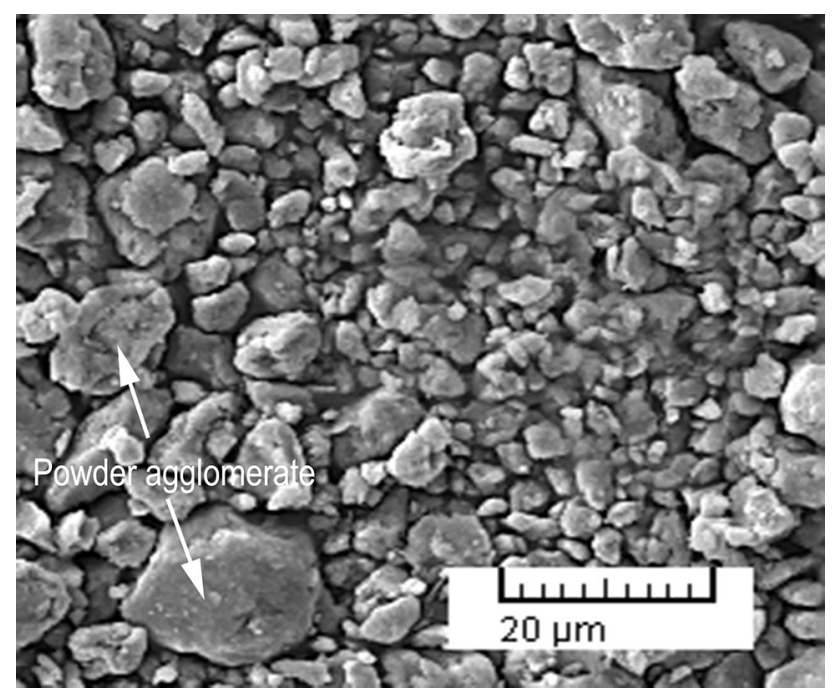

Fig. 6 Morphology of the mechanically alloyed powder

Also, densification caused isolated pores [22]. As a result, the presence of the pores became restricted and their sizes severely reduced. In MAA-TM2, similar coarser grains and isolated pores were observed. Also, a significant amount of the formed grains in MAA-TM1 and fewer grains in MAATM3 are near globular, but in MAA-TM3, almost no near globular grains were observed. Another important conclusion is about the intermetallic phases which are observed by white points in the thermomechanically processed samples. These phases were uniformly distributed in the two first cycles of the TMP. Nevertheless, in the third cycle, the distribution was not as uniform as those in MAA-
TM1 and MAA-TM2. As mentioned in Sect. 3.1, this may be due to the fact that more $\mathrm{Al}$ reacted with the other elements. In addition, the liquid-phase presence caused an increased diffusion rate, and as a result, the concentrations of $\mathrm{Zn}$ and $\mathrm{Mg}$ increased in the melt. Thus, by ending the process, the concentrated and reacted $\mathrm{Zn}$ and $\mathrm{Mg}$ in the melt solidify and form intermetallic phases. The EDS analysis results for points 1-4 in the SEM micrographs in Fig. 5 along with the relevant quantitative results in Table 2 confirm the XRD-detected phases in Fig. 7.

The average grain sizes of the samples which are presented in Fig. 8 can demonstrate the grain size evolution during the solid-state sintering and the TMP. The results showed that in MAA-s, the average grain size was about $25 \mu \mathrm{m}$. In the first cycle of the TMP, i.e., in MAA-TM1, it decreased to about $15 \mu \mathrm{m}$, and in the second cycle of the TMP, it was about $18 \mu \mathrm{m}$ although $10 \%$ liquid phase was present. However, in MAA-TM3, a noticeable growth occurred and the average grain size became about $27 \mu \mathrm{m}$. In fact, grain growth acceleration means that full density was almost reached [16]. In general, uniform distribution of the intermetallic phase particles in the microstructures in MAA-TM1 and MAA-TM2 caused grain boundary pinning

Table 2 Quantitative results of the EDS analysis (at $\%$ )

\begin{tabular}{lrrr}
\hline Point in Fig. 5 & Al & Zn & Mg \\
\hline 1 & 0 & 64 & 36 \\
2 & 0 & 83 & 17 \\
3 & 30 & 33 & 37 \\
4 & 24 & 21 & 55 \\
\hline
\end{tabular}



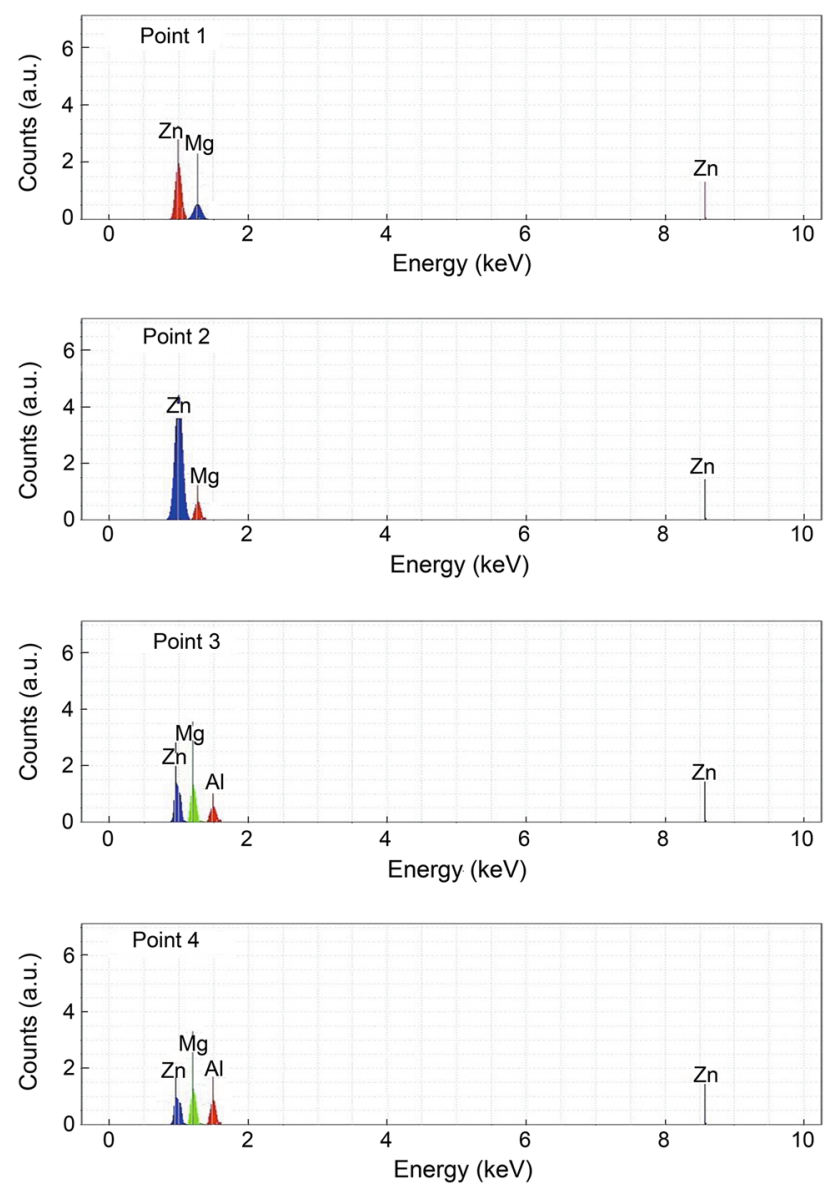

Fig. 7 EDS analysis results for points $1-4$ in Fig. 5

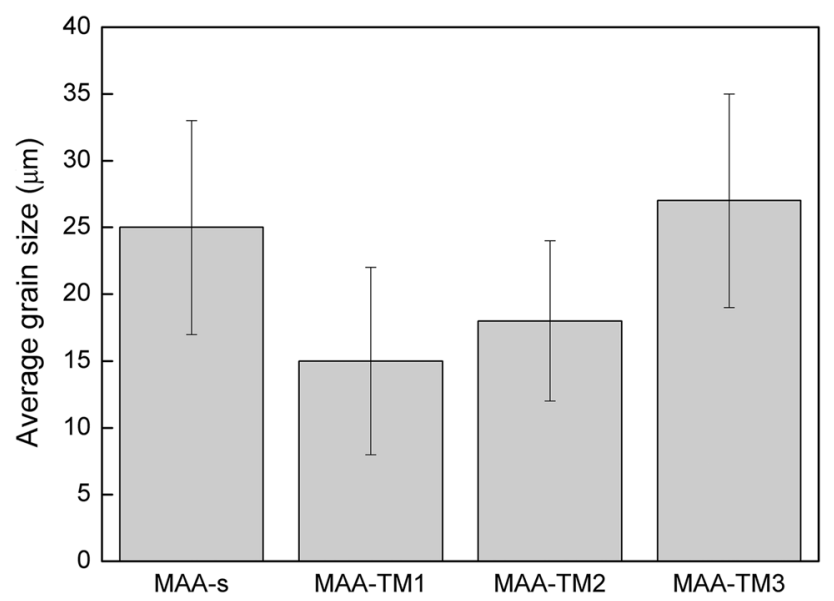

Fig. 8 Average grain sizes of the solid-state sintered and the thermomechanically processed samples

and inhibited severe grain growth, but in MAA-TM3 the uniform distribution of the intermetallic particles degraded and the grain size was higher than that in MAA-s. In other words, in this sample, the distribution volume of small particles was not enough to increase the pinning pressure and thus to hinder grain boundary mobility [23].
In brief, in equal times of solid-state sintering and the presence of the liquid phase, i.e., $90 \mathrm{~min}$, coarser grains were seen in the latter, but in shorter the presence of the liquid phase, i.e., $30 \mathrm{~min}$, the solid-state sintered sample consisted of coarser grains.

Comparing the results reported by some other researchers shows that finer grains were obtained in this study with the minimum grain size of about $15 \mu \mathrm{m}$. For example, Tzimas et al. [3] and Hassa-Irani [8] reached the minimum grain sizes of about 97 and $42 \mu \mathrm{m}$, respectively, by using SIMA method. Wang et al. [6] reported the grain sizes over $100 \mu \mathrm{m}$ in their research for 7075 alloy modified through isothermal holding method. Haghayeghi et al. [4] obtained the minimum grain size of about $35 \mu \mathrm{m}$ via mechanical stirring. Satyanarayana et al. [5] could manufacture the alloys with the grain size of $20-30 \mu \mathrm{m}$ via spray casting.

Another important result is Tzimas et al. [3] concluded that in SIMA, warm working is required for low ductility alloys. However, in this research, microstructure of a low ductility alloy was successfully modified by a process consisted of cold working.

Another look at Fig. 5 with attention to the right-sided images reveals the effects of pressure application in the TMP. In MAA-s, shape of the grains was equiaxed and similar to the micrograph of Fig. 5a. Moreover, grain boundary porosities were observed in this surface. By applying the TMP, pressing caused decreasing the amount of porosity in the thickness surface as well as pilling up the grain boundaries in some regions. This pilling up of the grain boundaries can be ascribed to the fact that smaller grains were compacted by pressure application and in some regions they were merged. This is obvious in Fig. 5d, f, h. As the number of the TMP cycles increased, population of the grain boundaries intensified and thicker boundaries were observed due to combining more grains. Another probability in this case was remelting the grain boundaries during the presence of the liquid phase. However, sintering resulted in decreasing the number of merged grains in some regions due to grain growth.

\subsection{Microhardness Measurement}

One of the most important mechanical properties which can represent the effects of the process on the samples is microhardness. Figure 9 presents the results of microhardness measurement for the solid-state sintered and thermomechanically processed samples in both directions, i.e., parallel with and perpendicular to the direction of pressure application. The results revealed that up to the second cycle of the TMP, in both directions microhardness increased, but it decreased in the third cycle. Also, higher amounts of microhardness were observed in the direction parallel with 


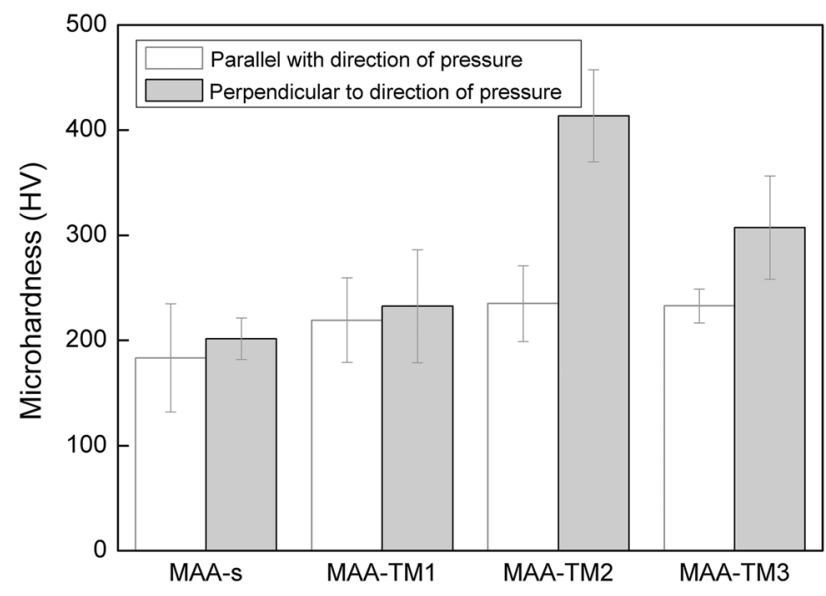

Fig. 9 Results of microhardness measurements

the direction of pressure application due to wok hardening caused by alternate cold pressing in this direction.

In MAA-s, the lowest value of microhardness was measured due to the presence of the grain boundary porosities (Fig. 5a, b). By application of the TMP and decreasing the amount and the size of these porosities, the amount of microhardness increased. Also, in the first and the second cycles of the TMP, because of formation of the intermetallic particles and uniform distribution of these particles, the microhardness values increased. Although these particles exist in MAA-TM3 grain growth decreased the hardness level according to the Hall-Petch equation. Also, the uniformity of intermetallic particles degraded and they were concentrated in some regions rather than uniform distribution in the microstructure (Fig. 5g). Moreover, in the direction parallel with the direction of pressure application, the number of the merged grains increased which resulted in formation of thick grain boundaries (Fig. 5h) which usually are of lower level of hardness.

\section{Conclusions}

Thermomechanical processing of the compact powders of Al-Zn-Mg nanostructured alloy was carried out. The TMP consisted of three cycles of cold pressing at $154 \mathrm{MPa}$ and liquid-phase sintering at $600{ }^{\circ} \mathrm{C}$. The most important conclusions are as follows:

(1) Solid-state sintering resulted in grain boundary porosities and the crystallite size and average grain size of about $29 \mathrm{~nm}$ and $25 \mu \mathrm{m}$, respectively.

(2) Similar phases with different amounts formed in the solid-state sintering and the TMP.

(3) The TMP caused smaller grain sizes in the first and the second cycles but coarser grains in the third cycle.

(4) Nanocrystallites were stable up to the second cycle of the TMP, but decreasing the porosity content and reaching almost full density caused above $100 \mathrm{~nm}$ crystallites in the third cycle.

(5) Application of pressure in the TMP caused merging of grains in the parallel direction with the direction of pressure application.

(6) The microhardness values of the thermomechanically processed samples were higher than those of the solid-state sintered sample. The maximum amount of microhardness was measured in the second cycle of the TMP because of uniform distribution of the intermetallic particles.

Acknowledgments The authors would like to thank the authorities of Institute of Science, High Technology and Environmental Sciences, Graduate University of Advanced Technology and also INSF (the No. 92006471) due to their attempts for financial support of this work.

\section{References}

[1] D. Kirkwood, Int. Mater. Rev. 39, 173 (1994)

[2] Z. Fan, Int. Mater. Rev. 47, 49 (2002)

[3] E. Tzimas, A. Zavaliangos, Materi. Sci. Engi. A 289, 217 (2000)

[4] R. Haghayeghi, E.J. Zoqui, A. Halvaee, M. Emamy, J. Mater. Process. Technol. 169, 382 (2005)

[5] K.G. Satyanarayana, S.N. Ojha, D. Naresh Nath Kumar, G.V.S. Sastry, Mater. Sci. Engi. A 304-306, 627 (2001)

[6] J.L. Wang, Y.H. Su, C.Y.A. Tsao, Scr. Mater. 37, 2003 (1997)

[7] C. Wang, H. Mei, R. Li, D. Li, L. Wang, J. Liu, Z. Hua, L. Zhao, F. Pen, H. Li, Acta Metall. Sin. (Engl. Lett.) 26, 149 (2013)

[8] S.B. Hassas-Irani, A. Zarei-Hanzaki, B. Bazaz, A.A. Roostaei, Mater. Des. 46, 579 (2013)

[9] J. Jiang, Y. Wang, J. Qu, Z. Du, Y. Sun, S. Luo, J. Alloys Compd. 497, 62 (2010)

[10] G.P. Chen, T.R. Zhou, H. Yan, F.Y. Zhang, Acta Metall. Sin. (Engl. Lett.) 21, 197 (2008)

[11] J.G. Wang, P. Lu, H.Y. Wang, Q.C. Jiang, Mater. Lett. 58, 3852 (2004)

[12] J.G. Wang, P. Lu, H.Y. Wang, J. Liu, Q.C. Jiang, J. Alloys Compd. 395, 108 (2005)

[13] S.J.L. Kang, Sintering, ed. by S.J.L. Kang (Butterworth-Heinemann, Oxford, 2005), p. 3

[14] J. Suri, L.L. Shaw, Ceram. Int. 40, 9179 (2014)

[15] Y. Xiong, H. Wang, Z. Fu, J. Eur. Ceram. Soc. 33, 2199 (2013)

[16] R.M. German, P. Suri, S.J. Park, J. Mater. Sci. 44, 1 (2009)

[17] X.J. Jiang, B. Noble, V. Hansen, J. Tafto, Metall. Mate. Trans. A 32, 1063 (2001)

[18] M.M. Sharma, C.W. Ziemian, T.J. Eden, J. Mater. Eng. Perform. 19, 1344 (2010)

[19] R. Flores-Campos, I. Estrada-Guel, M. Miki-Yoshida, R. Martínez-Sánchez, J.M. Herrera-Ramírez, Mater. Charact. 63, 39 (2012)

[20] C. Suryanarayana, Int. Mater. Rev. 40, 41 (1995)

[21] R.M. German, Sintering: From Empirical Observations to Scientific Principles (Butterworth-Heinemann, Boston, 2014), p. 355

[22] R.M. German, Sintering: From Empirical Observations to Scientific Principles (Butterworth-Heinemann, Boston, 2014), p. 247

[23] C. Koch, R. Scattergood, K. Darling, J. Semones, J. Mater. Sci. 43, 7264 (2008) 